\title{
Cloning of Candida albicans genes conferring resistance to azole antifungal agents: characterization of CDR2, a new multidrug ABC transporter gene
}

\author{
Dominique Sanglard, ${ }^{1}$ Françoise Ischer, ${ }^{1}$ Michel Monod ${ }^{2}$ \\ and Jacques Bille ${ }^{1}$ \\ Author for correspondence: Dominique Sanglard. Tel: +41 21 3144083. Fax: +41213144060. \\ e-mail: dsanglar@eliot.unil.ch
}

Institut de Microbiologie' and Service de

Dermatologie2, Centre Hospitalier Universitaire Vaudois (CHUV), 1011

Lausanne, Switzerland

\begin{abstract}
Resistance to azole antifungal agents in Candida albicans can be mediated by multidrug efflux transporters. In a previous study, we identified at least two such transporters, Cdr1p and Benp, which belong to the class of ATP-bininding cassette (ABC) transporters and of major facilitators, respectively. To isolate additional factors potentially responsible for resistance to azole antifungal agents in C. albicans, the hypersusceptibility of a Saccharomyces cerevisiae multidrug transporter mutant, $\Delta p d r 5$, to these agents was complemented with a C. albicans genomic library. Several new genes were isolated, one of which was a new ABC transporter gene called CDR2 (Candida drug resistance). The protein Cdr2p encoded by this gene exhibited $84 \%$ identity with Cdr1p and could confer resistance to azole antifungal agents, to other antifungals (terbinafine, amorolfine) and to a variety of metabolic inhibitors. The disruption of CDR2 in the C. albicans strain CAF4-2 did not render cells more susceptible to these substances. When the disruption of CDR2 was performed in the background of a mutant in which CDR1 was deleted, the resulting double $\Delta c d r 1 \Delta c d r 2$ mutant was more susceptible to these agents than the single $\Delta c d r 1$ mutant. The absence of hypersusceptibility of the single $\Delta c d r 2$ mutant could be explained by the absence of CDR2 mRNA in azole-susceptible C. albicans strains. CDR2 was overexpressed, however, in clinical C. albicans isolates resistant to azole antifungal agents as described previously for CDR1, but to levels exceeding or equal to those reached by CDR1. Interestingly, CDR2 expression was restored in $\Delta \mathrm{cdr} 1$ mutants reverting spontaneously to wildtype levels of susceptibility to azole antifungal agents. These data demonstrate that CDR2 plays an important role in mediating the resistance of C. albicans to azole antifungal agents.
\end{abstract}

Keywords: multidrug efflux transporters, azole antifungal agents, Candida albicans

\section{INTRODUCTION}

Candida albicans is an important opportunistic pathogen which can cause disseminated and mucosal infections in humans (Odds et al., 1990). Patients with compromised immune systems, for example, patients receiving organ transplants and cancer chemotherapy or

Abbreviations: ABC transporter, ATP-binding cassette transporter; 5FOA, 5 -fluoroorotic acid.

The GenBank accession number for the sequence reported in this paper is U63812. people infected by HIV, who see their immune system gradually affected by their illness, are particularly prone to such infections. C. albicans is the major agent of oropharyngeal candidiasis in AIDS patients. Oropharyngeal candidiasis is one of the most frequent fungal infections of recent years, since it occurs in up to $90 \%$ of AIDS patients during their life span (Vanden Bossche et al., 1994a). Among antifungal agents available to treat infections caused by C. albicans, fluconazole is by far the most commonly used compound (Powderly, 1994). The cellular target of fluconazole and other azole derivatives in yeast is a cytochrome P450 (CYP51A1), 
which is a haemoprotein involved in the $14 \alpha$-demethylation of lanosterol, an important step in the biosynthesis of ergosterol (Vanden Bossche et al., 1994b). As a consequence of the increasing number of infections caused by $C$. albicans, the use of this antifungal agent has been more widespread. Repeated treatments with fluconazole have led to the appearance of yeast isolates resistant to this agent in vitro (Johnson et al., 1995b; Odds, 1996; Rex et al., 1995; Vuffray et al., 1994). In a recent study investigating the mechanisms of resistance to fluconazole in C. albicans isolates from AIDS patients with oropharyngeal candidiasis, we could demonstrate that the majority of resistant C. albicans isolates failed to accumulate the intracellular levels of fluconazole reached in susceptible isolates. This phenomenon could be correlated with an enhanced fluconazole efflux. Two multidrug efflux transporters, the ATP-binding cassette $(\mathrm{ABC})$ transporter Cdr1p and the major facilitator Benp, were identified as possible mediators in this process (Sanglard et al., 1995). The genes for these transporters, $C D R 1$ and $B E N^{\mathrm{r}}$, have been isolated by Prasad et al. (1995) and Fling et al. (1991) and also in our laboratory by complementation of fluconazole hypersusceptibility of a Saccharomyces cerevisiae mutant lacking the ABC transporter Pdr5p/Sts1p (Sanglard et al., 1995).

We expected that other factors involving efflux drug transport or other mechanisms could be responsible for the resistance of C. albicans to azole antifungal agents. A number of other mechanisms involving alterations of the cellular target, CYP51A1, or alterations in the ergosterol biosynthetic pathway have been proposed (Marichal \& Vanden Bossche, 1995). Rather than comparing the physiology and biochemistry of azolesusceptible and azole-resistant $C$. albicans isolates, a more global strategy enabling the cloning of any $C$. albicans DNA sequences rendering the $S$. cerevisiae multidrug transporter mutant $\Delta p d r 5$ resistant to these agents was developed. The possible involvement of cloned genes in the resistance to azole antifungal agents could then be addressed in a panel of clinical isolates. Here, the results obtained using such a strategy and an extended characterization of one of the cloned genes, which was similar to CDR1 and therefore named $C D R 2$, are reported.

\section{METHODS}

Strains. C. albicans CAF4-2 (Aura3::imm434/

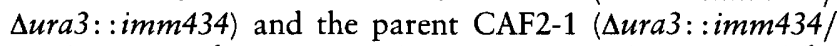
URA3) were from B. Fonzi (Fonzi \& Irwin, 1993). The S. cerevisiae strain YKKB-13 (MATa ura3-52 lys2-801 ${ }^{\text {amber }}$ ade2-101 ${ }^{\text {ochre }} \operatorname{trp} 1-\Delta 63$ his3- $\Delta 200$ leu2- $\Delta 1$ ssts1::TRP1) has been described by Bissinger $\&$ Kuchler (1994). The genotypes of other yeast strains are listed in Table 1. E. coli DH5 $\alpha$ (Hanahan, 1985) was used as a host for plasmid construction and propagation.

Media. C. albicans strains were grown on YEPD complex medium with $2 \%$ glucose, $1 \%$ Bacto peptone (Difco) and $0.5 \%$ yeast extract (Difco). YEPD agar plates contained $2 \%$ agar (Difco) as a supplement. Yeast Nitrogen Base (YNB; Difco) with $2 \%$ glucose and $2 \%$ agar (Difco) was used as a selective medium after transformation of C. albicans. Agar plates containing $50 \mu \mathrm{g} 5$-fluoroorotic acid $\left(5\right.$-FOA) $\mathrm{ml}^{-1}$ were made for the regeneration of the ura3 genetic marker in YNB selective medium with $50 \mu \mathrm{g}$ uridine $\mathrm{ml}^{-1}$.

Drug susceptibility testing. Susceptibility of C. albicans strains to different compounds was tested qualitatively by spotting serial dilutions of yeast cultures in complex YEPD medium agar plates, which provides an easy visualization of growth differences between different yeast strains. The following drugs were solubilized in DMSO: ketoconazole and itraconazole (Janssen Pharmaceuticals), terbinafine (Sandoz Pharma), and nocodazole, brefeldin A, cerulenin and 4nitroquinoline $\mathrm{N}$-oxide (Sigma). Fluconazole (Pfizer), amorolfine chloride (Hoffmann-La Roche) and crystal violet (Sigma) were dissolved in water. Each plate contained $15 \mathrm{ml}$ agar. The drugs were diluted in the corresponding solvents to achieve the concentrations used in YEPD plates. Preliminary tests were performed to optimize drug concentrations in YEPD plates so that growth differences between the different $C$. albicans strains used in this study could be observed. To perform the susceptibility tests, yeasts were grown overnight at $30^{\circ} \mathrm{C}$ with constant shaking in YEPD liquid medium. The cultures were diluted to $2 \times 10^{7}$ cells $\mathrm{ml}^{-1}$ in $0.9 \% \mathrm{NaCl}$. Five microlitres of this suspension and of serial dilutions of each yeast culture was spotted on each type of plate and incubated for a given time at $30^{\circ} \mathrm{C}$.

Accumulation of fluconazole in yeast. Accumulation experiments of $\left[{ }^{3} \mathrm{H}\right]$ fluconazole (Amersham) in C. albicans CAF2-1 and in multidrug transporter mutants were performed as described previously (Sanglard et al., 1995), except that $20 \mathrm{~min}$ incubation was chosen as the single sampling time. Each accumulation experiment was repeated twice.

Construction of plasmids. For the disruption of CDR2 in C. albicans, a $2.4 \mathrm{~kb}$ SpeI-KpnI fragment from pDS246 was subcloned in pBluescript $\mathrm{KS}(+)$ to yield pDS346. An internal $0.9 \mathrm{~kb}$ HindIII-PstI fragment from pDS346 was replaced by the hisG-URA3-bisG disruption cassette from pMB-7 (Fonzi \& Irwin, 1993) to create pDS368. The linear 5.2 kb SpeI-KpnI fragment from pDS368 was used for disruption experiments.

Sequencing. Sequencing reactions were performed on both DNA strands by standard protocols using an AutoRead kit (Pharmacia). The reactions were analysed on an ALF automated station (Pharmacia). Sequences were obtained by primer elongation using synthesized primers (Microsynth).

Yeast transformation. For gene disruptions, C. albicans CAF4-2 was transformed with linear fragments by an LiAc procedure developed in our laboratory. Yeast were grown to mid-exponential phase to a density of $2 \times 10^{7}$ cells ml ${ }^{-1}$ in $100 \mathrm{ml}$ YEPD complex medium with constant shaking at 250 r.p.m. Fifty millilitres of this culture was removed to a $50 \mathrm{ml}$ Falcon tube and centrifuged at 5000 r.p.m. at $4^{\circ} \mathrm{C}$ for $5 \mathrm{~min}$. The pellet was washed twice with TE buffer $(10 \mathrm{mM}$ Tris $/ \mathrm{HCl}$, pH 7.5; $1 \mathrm{mM}$ EDTA). Another washing was performed with $10 \mathrm{ml} \mathrm{Li} / \mathrm{TE}$ buffer $(0 \cdot 1 \mathrm{M} \mathrm{LiAc}$ in TE, $\mathrm{pH} 7 \cdot 5)$. The final cell pellet was resuspended in $200 \mu \mathrm{l} \mathrm{Li} / \mathrm{TE}$ buffer and placed on ice. Yeast suspension $(50 \mu l)$ was aliquoted into Eppendorf tubes. The following reagents were added sequentially to each tube: $300 \mu \mathrm{l}$ of freshly prepared PEG buffer ( $40 \%$ PEG 4000 in Li/TE buffer), $5 \mu \mathrm{l} 10 \mathrm{mg}$ sheared herring sperm DNA (Clontech) $\mathrm{ml}^{-1}$, then linear DNA fragments $(1-2 \mu \mathrm{g})$ in a maximum volume of $5 \mu \mathrm{l}$. The tubes were mixed gently and incubated for $30 \mathrm{~min}$ at $30^{\circ} \mathrm{C}$. After heat shock at $42{ }^{\circ} \mathrm{C}$ for $20 \mathrm{~min}$, the tubes were centrifuged briefly three times in a microcentrifuge at room temperature. 
Table 1. Genotypes of yeast strains used in this study

\begin{tabular}{|c|c|c|c|}
\hline Strain name & Parent strain & Genotype & Reference \\
\hline CAF2-1 & SC5314 & $\Delta u r a 3:: i m m 434 / U R A 3$ & Fonzi \& Irwin (1993) \\
\hline CAF4-2 & CAF2-1 & $\Delta u r a 3:: i m m 434 / \Delta u r a 3:: i m m 434$ & Fonzi \& Irwin (1993) \\
\hline DSY 448 & DSY447 & 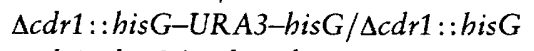 & Sanglard et al. (1996) \\
\hline DSY449 & DSY448 & $\Delta c d r 1::$ hisG $/ \Delta c d r 1::$ his $G$ & Sanglard et al. (1996) \\
\hline DSY649 & CAF4-2 & $\Delta c d r 2:$ hisG-URA3-bisG/CDR2 & This study \\
\hline DSY651 & DSY649 & $\Delta c d r 2::$ hisG $/ C D R 2$ & This study \\
\hline DSY653 & DSY651 & $\Delta c d r 2::$ hisG-URA3-bis $G / \Delta c d r 2::$ his $G$ & This study \\
\hline DSY650 & DSY449 & $\begin{array}{l}\Delta c d r 1:: \text { bisG } / \Delta c d r 1: \text { :bisG } \\
\Delta c d r 2:: \text { hisG-URA3-bisG/CDR2 }\end{array}$ & This study \\
\hline DSY652 & DSY650 & $\begin{array}{l}\Delta c d r 1:: \text { his } G / \Delta c d r 1:: \text { his } G \\
\Delta c d r 2:: \text { his } G / C D R 2\end{array}$ & This study \\
\hline DSY654 & DSY652 & 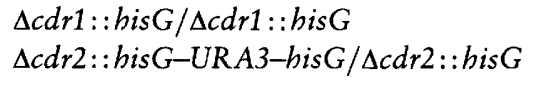 & This study \\
\hline
\end{tabular}

The supernatant was removed and the cell pellet was resuspended in $200 \mu \mathrm{TE}$. Aliquots of this suspension were plated in YNB selective medium and incubated for 3-4 d at $30^{\circ} \mathrm{C}$.

Plasmid rescue from S. cerevisiae. Episomal plasmids from the parent vector YEp24 were rescued from S. cerevisiae transformants by electroporation. Yeast were grown in selective YNB medium to late-exponential phase and total DNA was extracted as outlined below. DNA suspension $(1 \mu \mathrm{l})$ was electroporated into $E$. coli $\mathrm{DH} 5 \alpha$ and ampicillin-resistant clones from each transformant were analysed by restriction enzyme analysis.

Chromosome and RNA electrophoresis, Northern blot hybridizations and quantification. Chromosomes of $C$. albicans were separated for gene mapping by the clamped homogeneous electric field technique (CHEF-DRII; Bio-Rad) as described by Monod et al. (1994).

For Northern blots, total RNA from yeast was extracted and electrophoresed following the method described in Sanglard $e t$ al. (1995). Transfer of RNA was performed by capillarity on GeneScreen Plus membranes (DuPont NEN). Membranes were pre-hybridized at $42{ }^{\circ} \mathrm{C}$ with a buffer consisting of $50 \%$ formamide, $1 \%$ SDS, $4 \times$ SSC, $10 \%$ dextran sulfate and $100 \mu \mathrm{g}$ salmon sperm DNA ml ${ }^{-1}$. [ $\left.{ }^{32} \mathrm{P}\right] \mathrm{DNA}$-labelled probes were generated by random priming (Feinberg \& Vogelstein, 1984) and added to the hybridization solution overnight. Washing steps were at high stringency, identical with those recommended by the supplier (DuPont NEN). In Northern blots, the TEF3 mRNAs were analysed using a $0.7 \mathrm{~kb}$ EcoRI-Pst I fragment from $\mathrm{pDC1}$ as described by Hube $e t$ al. (1994). Stripping of probes in sequential hybridizations was achieved by boiling the membranes for $10 \mathrm{~min}$ in $0.1 \%$ SDS in TE buffer. Details about other probes are described in the legend of the corresponding figures.

Quantifications of Northern blots were performed by exposure of the hybridized membranes in an Instant Imager (Packard Instrument). Signals were integrated by the software supplied by the manufacturer and normalized to the corresponding values of the TEF3 internal standard.

PCR. PCR buffers and AmpliTaq polymerase were from Perkin Elmer (Roche Molecular Systems). The buffer composition was $10 \mathrm{mM}$ Tris $/ \mathrm{HCl}$ (pH 8.3), $50 \mathrm{mM} \mathrm{KCl}$ and $1.5 \mathrm{mM}$ $\mathrm{MgCl}_{2}$ containing $0.2 \mathrm{mM} \mathrm{dNTPs}$ and $2.5 \mathrm{U}$ polymerase per reaction. Briefly, the PCR was carried out in a Thermal Cycler 480 (Perkin Elmer) with a first cycle of denaturation for $4 \mathrm{~min}$ at $94^{\circ} \mathrm{C}$ followed by 30 cycles of annealing at $54^{\circ} \mathrm{C}$ for $2 \mathrm{~min}$, elongation at $72^{\circ} \mathrm{C}$ for $2 \mathrm{~min}$ and denaturation at $94^{\circ} \mathrm{C}$ for $30 \mathrm{~s}$. PCR was completed by a final elongation step at $72^{\circ} \mathrm{C}$ for $10 \mathrm{~min}$. Primers for PCR are described in Fig. 5 and were designed on the basis of the C. albicans CDR2 and Salmonella typhimurium bis $G$ nucleotide sequences in the GenBank database.

Yeast DNA templates for PCR were prepared from overnight cultures on complex medium. A $1 \mathrm{ml}$ portion of these cultures was centrifuged in an Eppendorf tube and DNA was extracted by adding $0.3 \mathrm{~g}$ glass beads, $200 \mu \mathrm{l}$ of a breaking buffer $(2 \%$ Triton X-100, $1 \%$ SDS, $10 \mathrm{mM}$ Tris/HCl, pH 8.0, $1 \mathrm{mM}$ EDTA, $100 \mathrm{mM} \mathrm{NaCl}$ ) and $200 \mu \mathrm{l}$ phenol/chloroform/ isoamyl alcohol ( $24: 24: 1$, by vol.). After $1 \mathrm{~min}$ vortexing, the tubes were centrifuged at maximum speed for $10 \mathrm{~min}$ in the microcentrifuge and the supernatant was re-extracted with chloroform/isoamyl alcohol $(24: 1, \mathrm{v} / \mathrm{v})$. Nucleic acids were then precipitated with ethanol and resuspended in $50 \mu \mathrm{l} \mathrm{TE}$. Of this suspension, $1 \mu \mathrm{l}$ was used for PCR.

\section{RESULTS}

\section{Cloning of $C$. albicans genes conferring resistance to azole antifungal agents}

We reported recently than an $S$. cerevisiae mutant YKKB-13 lacking the $A B C$ transporter Pdr5p was hypersusceptible to azole antifungal agents (Sanglard et al., 1995). This phenotype seemed to be adequate for complementing hypersusceptibility with any C. albicans DNA segment carrying genes of resistance to azole antifungal agents. These genes are thus likely to encode multidrug efflux transporters; however, they may belong to totally unrelated genes. A C. albicans genomic library from strain SC5314 was therefore constructed in the episomal vector YEp24 (Sanglard et al., 1995) and the resulting library was transformed in the $S$. cerevisiae strain YKKB-13. A total of $40000 \mathrm{Ura}^{+}$clones was obtained and spotted in selective YNB plates containing in a first screening $10 \mu \mathrm{g}$ fluconazole $\mathrm{ml}^{-1}$. Thirty-two azole-resistant clones emerged and their plasmids were 
Table 2. At least six C. albicans genes confer resistance to azole antifungal agents and other metabolic inhibitors in S. cerevisiae

Growth was recorded as positive by the presence of confluent colonies or single colonies with a visible diameter after $2 \mathrm{~d}$ incubation at $30^{\circ} \mathrm{C}$. Spotting of cells on plates was performed as described in Methods for drug susceptibility assays. Values: 4, growth at dilution $10^{-4} ; 3$, growth at $10^{-3} ; 2$, growth at $10^{-2} ; 1$, growth at $10^{-1} ; 0$, growth at $10^{-0} ;-$, no growth at $10^{-0}$.

\begin{tabular}{|c|c|c|c|c|c|c|c|}
\hline \multirow[t]{2}{*}{ Substance ${ }^{*}$} & \multicolumn{7}{|c|}{ Plasmid } \\
\hline & YEp24 & pDS243 & pDS239 & pDS246 & pDS255 & pDS257 & $\mathrm{pDS} 270 \dagger$ \\
\hline YEPD only & 4 & 4 & 4 & 4 & 4 & 4 & 4 \\
\hline Flu $(5)$ & - & 4 & 4 & 2 & 4 & 2 & 1 \\
\hline Itra $(0.025)$ & - & 4 & - & 2 & - & - & 1 \\
\hline Keto $(0.05)$ & - & 3 & - & 3 & - & - & 1 \\
\hline Cyh $(0.025)$ & - & 4 & 4 & 2 & 3 & 2 & - \\
\hline NQO $(50)$ & - & - & 4 & - & - & - & - \\
\hline Ben $(50)$ & - & - & 4 & - & - & - & - \\
\hline Terb (8) & 0 & 4 & 3 & 2 & 1 & 1 & 1 \\
\hline Amo $(0.05)$ & - & 3 & 0 & 1 & - & - & - \\
\hline Sum $(50)$ & 0 & 3 & 4 & 0 & 2 & 0 & 0 \\
\hline Flup (10) & - & 4 & 2 & 3 & - & - & - \\
\hline Phe $(10)$ & - & - & 4 & - & - & - & - \\
\hline Rho (5) & - & 4 & - & 2 & - & - & 1 \\
\hline Cer $(0 \cdot 5)$ & 0 & 4 & 4 & 4 & 2 & 4 & 0 \\
\hline Bref $(25)$ & 2 & 4 & 4 & 4 & 4 & 4 & 2 \\
\hline Cry $(0.05)$ & - & 0 & - & 2 & - & - & - \\
\hline
\end{tabular}

*Abbreviations for substances are followed by a number giving the concentration in $\mu \mathrm{g} \mathrm{ml}^{-1}$ used in YEPD medium. Amo, amorolfine; Ben, benomyl; Bref, brefeldin A; Cer, cerulenin; Cry, crystal violet; Cyh, cycloheximide; Itra, itraconazole; Flu, fluconazole; Flup, fluphenazine; Keto, ketoconazole; NQO, 4-nitroquinoline N-oxide; Phe, 1,10-phenanthroline; Rho, rhodamine 6G; Sum, sulfomethuron methyl; Terb, terbinafine.

† pDS270 was isolated by ketoconazole-resistance selection.

rescued in E. coli DH5 $\alpha$ by electroporation. Plasmids with unique and not overlapping restriction sites were selected and re-transformed in YKKB-13. After this selection, five different plasmids, each potentially carrying a unique resistance gene, were isolated. The same screening procedure was used with $0.2 \mu \mathrm{g}$ ketoconazole $\mathrm{ml}^{-1}$ in selective YNB medium. This procedure yielded plasmids, some of them with the same profiles as those obtained by fluconazole selection. However, one additional unique plasmid with a resistance gene was isolated, bringing the total number of resistance genes to six. Table 2 summarizes the pattern of resistance produced by each of these plasmids in YKKB-13, not only to azole antifungal agents but also to other antifungals and different metabolic inhibitors. All plasmids conferred resistance to fluconazole but to different degrees; for example, the presence of pDS243, pDS239 and pDS255 in YKKB-13 allowed cells to grow at all dilutions tested in a medium with $5 \mu \mathrm{g}$ fluconazole $\mathrm{ml}^{-1}$ whereas cells containing pDS246, pDS257 and pDS270 exhibited visible growth only up to dilutions of $10^{-2}$ and $10^{-1}$. While pDS239, pDS255 and pDS257 yielded specific resistance to fluconazole, only pDS243, pDS246 and pDS270 could confer cross-resistance to all three azole derivatives used in this study, but to different extents. pDS243 and pDS239, whose restriction maps are shown in Fig. 1, have been reported in a previous study and contained the CDR1 and $B E N^{\mathrm{r}}$ genes (Sanglard et al., 1995). CDR1 had previously been cloned by Prasad et al. (1995) by complementation of cycloheximide hypersusceptibility of an $S$. cerevisiae $\triangle p d r 5$ mutant, while $B E N^{\mathrm{r}}$ was cloned by Fling et al. (1991) in experiments where resistance to benomyl was conferred to another $S$. cerevisiae strain. The pattern of resistance of yeast transformed by the CDR1-containing plasmid pDS243 covers a wide range of substances (Table 2). This feature is typical of multidrug transporters of the ABC family, but among these substances are amorolfine and terbinafine, which are antifungals of medical relevance (Vanden Bossche et al., 1994b), sulfomethuron methyl, rhodamine $6 \mathrm{G}$, cerulenin and brefeldin A. These compounds have not yet been reported as substrates for this transporter. pDS239, which contained $B E N^{\mathrm{r}}$, besides conferring resistance to already reported substances such as cycloheximide, benomyl and 4-nitroquinoline $N$-oxide (Goldway $e t$ al., 1995), could also accept as new substrates terbinafine, sulfomethuron methyl, 1,10-phenanthroline, cerulenin and brefeldin A (Table 2). Among these new substrates, terbinafine, sulfomethuron methyl, cerulenin and brefeldin A can be used as substrates by both multidrug transporter classes. Specific substrates for Benp are 


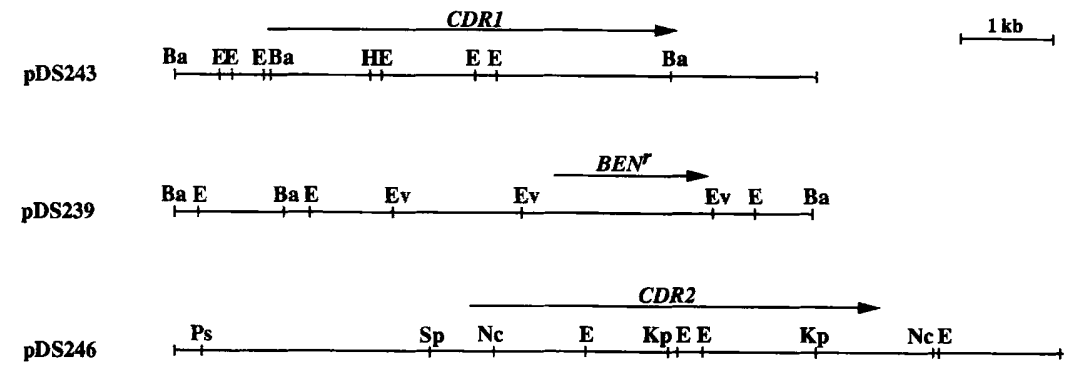

Fig. 1. Restriction maps of C. albicans insert DNA from plasmids conferring resistance to fluconazole in the $S$. cerevisiae $\Delta p d r 5$ mutant YKKB-13 (see Table 2). Only maps of pDS243, pDS239 and pDS246 are shown here. Ba, BamHI; E, ECoRI; Ev, EcoRV; $\mathrm{H}$, HindIII; Nc, Ncol; Kp, Kpnl; Ps, Pstl; Sp, Spel. Plasmids pDS243 and pDS239 contained the $C D R 1$ and $B E N^{r}$ genes, whose restriction maps are identical to those reported by Prasad et al. (1995) and by Fling et al. (1991), respectively. pDS246 contained the CDR2 gene. The CDR2 sequenced segment (Fig. 2) is indicated by a dotted line. Positions and transcription directions of the ORF of each gene are shown by arrows. benomyl, 1,10-phenanthroline and 4-nitroquinoline $\mathrm{N}$ oxide.

pDS246 conferred resistance to all azole derivatives, as mentioned above, and to a very similar variety of other metabolic inhibitors as CDR1, but with less potency than this gene. However, pDS246 seemed to confer a specific resistance to crystal violet (Table 2). Restriction mapping of pDS246 was performed (Fig. 1) and sequence analysis showed that an ORF encoding 1499 aa was present in the insert of this plasmid (see also Fig. 2). This ORF had a high identity (84\%) to that in CDR1 (Prasad et al., 1995) and therefore it was named CDR2.

The genes carried by the other plasmids listed in Table 2 , namely pDS255, pDS257 and pDS270, contained, according to the data available from total or partial nucleotide sequences, unidentified $C$. albicans genes when compared with the current GenBank database (this will be reported elsewhere). In this study, we focused only on $C D R 2$, since it is closely related to CDR1 and is possibly involved in resistance to azole antifungal agents in clinical C. albicans isolates.

\section{Sequence analysis of CDR2}

A 5800 bp NlaIV-EcoRI fragment from pDS246, which was expected from partial nucleotide sequence analysis to contain the entire CDR2 gene, was subcloned with available restriction sites and its nucleotide sequence was determined. An uninterrupted ORF of $4500 \mathrm{bp}$ starting from the most upstream ATG codon was observed in this fragment. The 5'-flanking region starting from this ATG codon displayed conserved features of typical yeast promoters: an adenosine at position -3 and a TATA box at position -111 (Chen \& Struhl, 1988) could be clearly distinguished. Interestingly, in the 3'-flanking region of the nucleotide sequence in Fig. 2 , an ORF beginning at +4850 has high similarity with the ORF e242682 of unknown function in $S$. cerevisiae.

$C D R 2$ maps, as in the case of CDR1, on chromosome 3 of the C. albicans genome, as determined by chromosome separation by the clamped homogeneous electric field technique and by mapping on a fosmid database ( $\mathrm{S}$.
Scherer, personal communication; data available at URL http://alces.med.umn.edu/bin/genelist?genes).

The CDR2 ORF encodes a protein of $168 \mathrm{kDa}$ and displays a structure and domain organization typical of membrane proteins of the $A B C$ superfamily. It is $84 \%$ identical and $92 \%$ similar to $\mathrm{Cdr} 1 \mathrm{p}$; however, alignment of the two amino acid sequences shows that the $\mathrm{N}$ - and C-terminal portions of both proteins were more divergent (Fig. 3). As in the case of Cdr1p, Cdr2p is composed of two homologous halves, each comprising a C-hydrophilic and an N-hydrophobic domain. The hydropathy plot of Cdr2p identified six putative transmembrane domains for each of the hydrophobic domains (see Fig. 2). Each hydrophilic domain included ATP-binding motifs found in ATP-binding cassette domains. In the $\mathrm{N}$-terminal ABC domain, the Walker $\mathrm{A}$ (GRPGAGCST) and B (IQCVD) motifs and the ABC signature (VSGGERKRVSIA) are identical in both proteins. In the C-terminal ABC domain, both the Walker A (GASGAGKT) and Walker B (LLFLD) regions are present in both proteins, but no typical $A B C$ signature is present.

The high similarity between the amino acid sequences of Cdr1p and Cdr2p does not, however, extend to the regions flanking the ORF of both genes. The $5^{\prime}$-flanking and promoter regions of both genes are especially divergent and thus suggest that these genes may differ in their regulation.

\section{Expression of CDR2 in clinical C. albicans isolates}

To address the possible expression of CDR2 in $C$. albicans, two pairs of C. albicans clinical isolates were selected, each of which contained closely related isolates susceptible and resistant to azole antifungal agents. These strains were isolated from two different AIDS patients with oropharyngeal candidiasis and were analysed in a previous study in which the resistant isolate of each pair was reported to overexpress CDR1 (Sanglard et al., 1995). Total RNA from the isolates was extracted and subjected to Northern blot analysis with probes specific for $C D R 1$ and $C D R 2$. These probes were of identical length and spanned the same $5^{\prime}$-flanking 


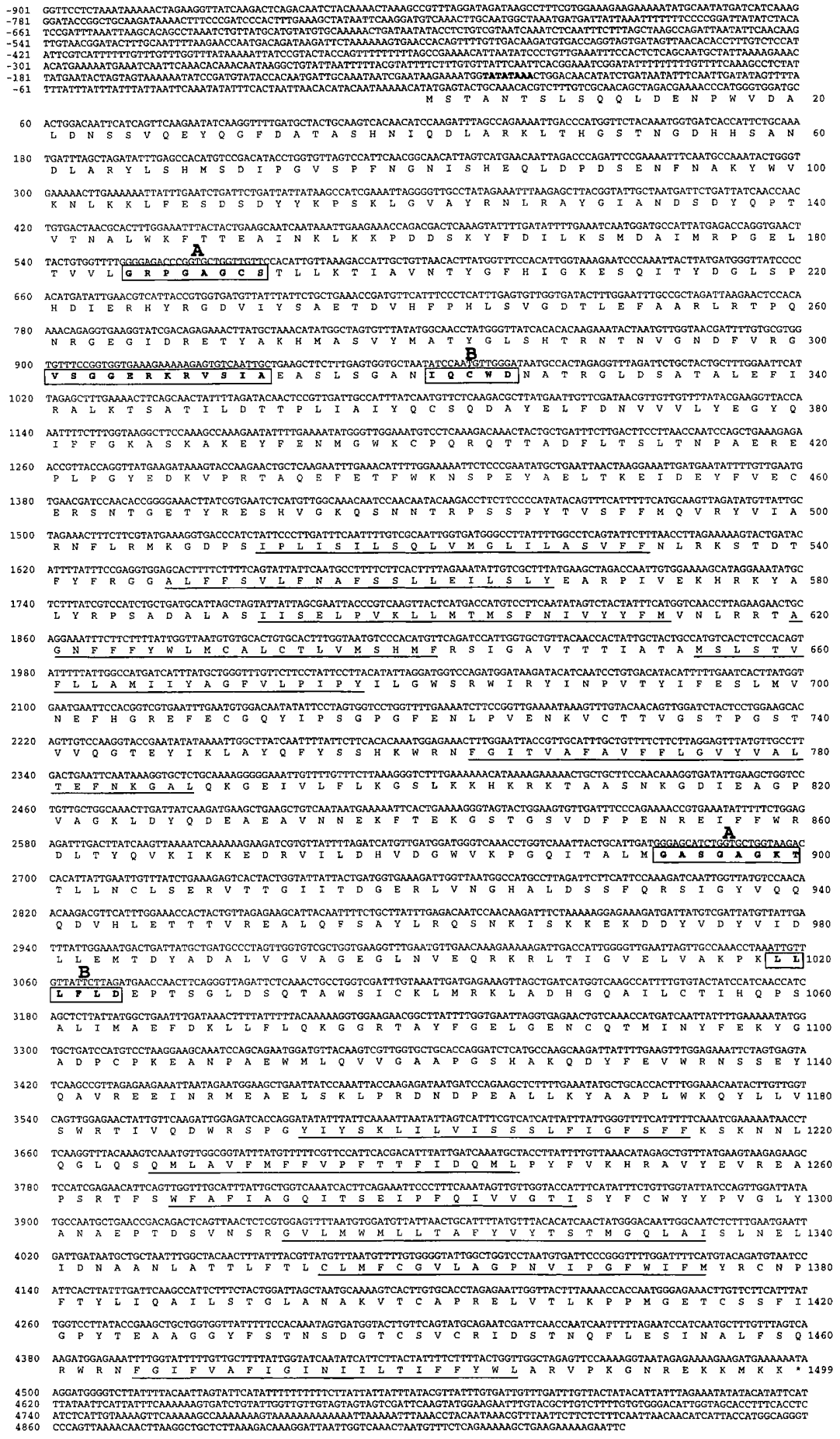

Fig. 2. Nucleotide and deduced amino acid sequences of the CDR2 gene and its encoded polypeptide. Nucleotides and amino acids are numbered to the left and to the right side, respectively. The sequence starts from a NlalV site and ends with an EcoRI site (see also Fig. 1). The position of the CDR2 ORF in the CDR2 restriction map corresponds to the arrow shown in Fig. 1. In the deduced protein sequence, putative membranespanning domains are underlined; the Walker A and B ATP-binding motifs and one $A B C$ signature are boxed in the $N$ - and $C$ terminal regions. A TATA box in the 5'flanking region is indicated in bold. CUG codons encoding serine in C. albicans are at positions $+61,+1894$ and +2362 . regions of both genes, where the degree of homology between the two genes is very low. Thus, no crosshybridization between the two probes could be expected. As presented in Fig. 4, CDR1 was expressed constitutively but at low levels in strains still susceptible to azole antifungal agents and, as expected, increased expression was observed when the isolates of each pair became resistant to the same agents. Quantifications with the Instant Imager (see Methods) revealed that the expression of CDR1 was increased in C34 over C26 and in C56 over C43 by $2 \cdot 7$-fold and $4 \cdot 5$-fold, respectively, thus confirming results obtained in a previous study with the same strains (Sanglard et al., 1995). Conversely CDR2 was not expressed in the same susceptible isolates, and most surprisingly, this gene was overexpressed when the isolates became resistant to azole antifungal agents. The relative $C D R 2 \mathrm{mRNA}$ levels exceeded those of CDR 1 by a factor of 6 in isolate C26 and only slightly those of CDR 1 , by a factor of $1 \cdot 3$, in isolate C56. 


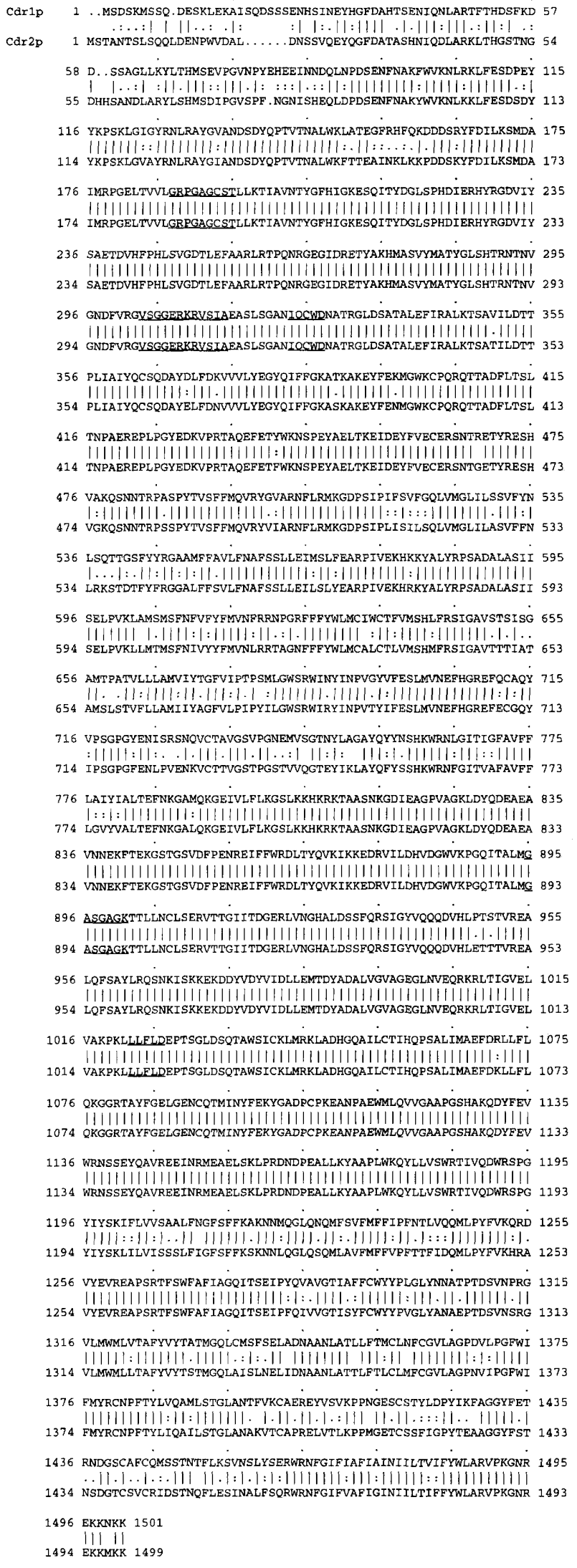

Fig. 3. Alignment of the $C$. albicans multidrug resistance proteins Cdr1p and $C d r 2 p$. Identical amino acid residues are

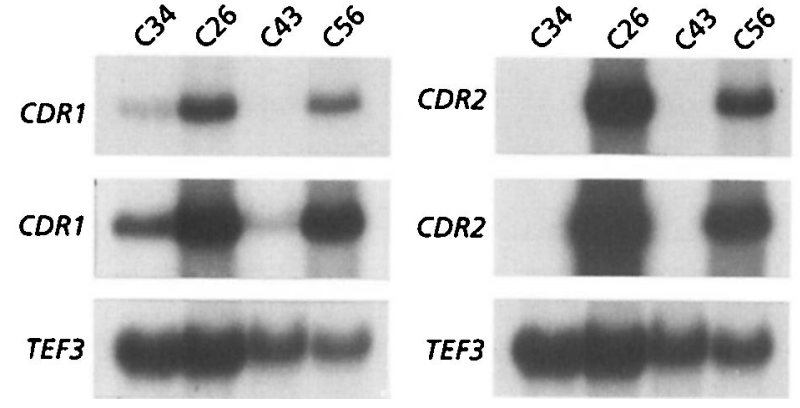

Fig. 4. Northern blot analysis of C. albicans clinical isolates susceptible and resistant to azole antifungal agents. Isolates C34 and C26, and C43 and C56 are azole-susceptible and azoleresistant pairs from two distinct patients. These strains have been characterized and have been tested for their susceptibility to fluconazole, itraconazole and ketoconazole as described previously (Sanglard et al., 1995). The Northern blot was probed sequentially with $C D R 1$ and $C D R 2$ probes and finally a TEF3 probe as an internal standard for normalization of the loaded quantities. Specific CDR1 and CDR2 probes were generated by PCR with primers spanning the nucleotide regions -109 to +280 and -112 to +274 with respect to the first ATG initiation codon of the published sequences. The identity between the two probes at the level of the nucleotide sequence is below $50 \%$. The figure shows the signal intensities obtained with the CDR1 and CDR2 probes after 9 and $18 \mathrm{~h}$ exposure of membranes on an RX Fuji X-ray film at $-70^{\circ} \mathrm{C}$. Signal intensities with the TEF3 probes were obtained after $3 \mathrm{~h}$ exposure on the same $X$-ray film.

\section{Disruption of the CDR2 gene}

To investigate the effect of Cdr2p in C. albicans, the gene encoding this protein was deleted by targeted gene disruption by the method described by Fonzi \& Irwin (1993). CAF4-2, and also a strain named DSY449 (Table 1) in which both alleles of CDR1 were deleted (Sanglard et al., 1996), were utilized as recipients for transformation with a linear fragment in which a substantial region of $C D R 2$ was deleted and replaced by the hisG-URA3-hisG URA3-blaster disruption cassette (see Fig. 5). An LiAc transformation protocol was utilized here and yielded approximately $100 \mathrm{Ura}^{+}$transformants $(\mu \mathrm{g} \text { linear fragment })^{-1}$. A PCR method was applied in this study to screen Ura ${ }^{+}$transformants for the correct localization of the disruption of the first CDR2 allele. This approach consisted of using a pair of primers where one was specific for the bis $G$ gene and the other would anchor a site flanking the region of homologous recombination between the genomic locus and the linear DNA fragment (see Fig. 5). Ten Ura ${ }^{+}$transformants for each disruption in CAF4-2 and DSY449 were screened and they all showed the correct genotype. PCR analysis of only one of these clones for each disruption strategy

marked by a bar. Colons and periods indicate high and low conservative replacements between the two proteins. Walker $A$ and $B$ domains and the $A B C$ signature are underlined. The alignment was generated by the method of Needleman \& Wunsch (1970) implemented in the program GAP of the GCG package of the University of Wisconsin. 
$1 \mathbf{k b}$
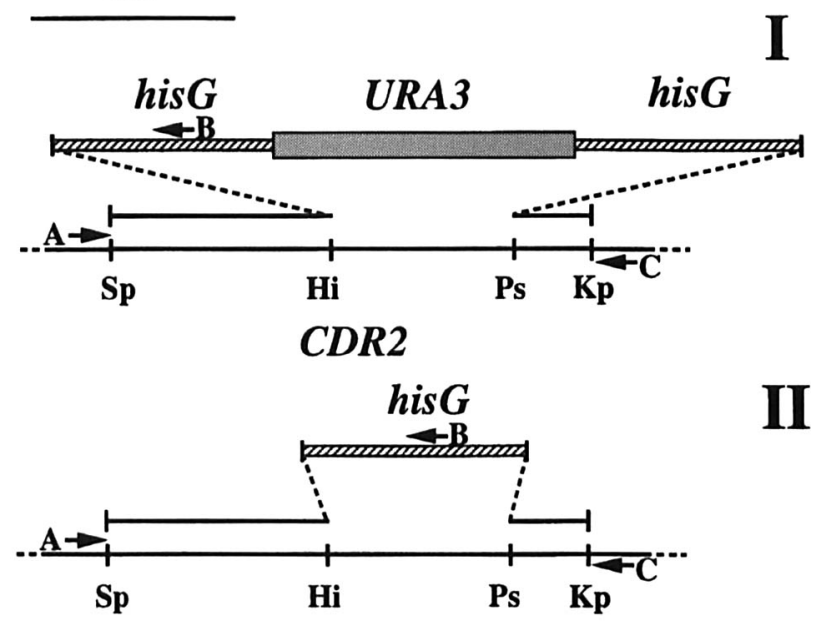

CDR2

Fig. 5. Restriction maps of the CDR2 alleles in disruption experiments. Parts I and II are schematic representations of the disruption of the CDR2 gene before and after regeneration of the ura3 genetic marker by selection with 5-FOA. The maps of the wild-type alleles are shown with the corresponding disrupted alleles. The location of the primers $A\left(5^{\prime}-\right.$ ATTCAATTCACGGAAATCGGATA-3'; CDR2-specific), B (5'GGCGCGACTICGACAGAAC-3', hisG-specific) and $\mathrm{C}$ (5'GTGCACAGTGCACACATTAACC-3', CDR2-specific) used in PCR for the monitoring of disruption (Fig. 6) is indicated. The linear fragment containing the gene deletion construct as represented in panel 1 and which was used for disruption experiments was the $5.2 \mathrm{~kb}$ Spel-Kpnl fragment from pDS368.

(DSY649 and DSY650) is shown in Fig. 6. As expected, PCR performed with primers $\mathrm{A}$ (specific for the CDR2 gene) and $\mathrm{B}$ (specific for the his $G$ gene) with genomic DNA of these strains yielded a major PCR product of $1.6 \mathrm{~kb}$. One positive transformant of each first allele disruption was further treated with 5-FOA to regenerate the ura3 genetic marker. The regeneration of the ura3 marker by recombination between his $G$ repeats rather than by mitotic recombination between the wild-type allele and the first disrupted alleles was verified on 5FOA-resistant strains by PCR analysis. In each case, four 5-FOA-resistant clones were analysed and all had the desired genotype. Only PCR analysis of one representative of each marker regeneration (DSY651 and DSY652) is shown on Fig. 6. PCR products from DSY651 and DSY652 using primers $A$ and $C$ (both specific for CDR2) were obtained with sizes of $2 \cdot 1$ and $2 \cdot 4 \mathrm{~kb}$, corresponding to the sizes expected from the wild-type allele and the $\Delta c d r 2::$ his $G$ disrupted allele, respectively.

The linear fragment containing the CDR2 deletion construct was then re-used for the disruption of the second CDR2 allele in both cases. PCR analysis was used again to select Ura ${ }^{+}$transformants where both alleles were disrupted. On this selection basis, the $\mathrm{Ura}^{+}$ $\Delta c d r 2$ and $\Delta c d r 1 \Delta c d r 2$ homozygous deletion mutants DSY653 and DSY654 could be successfully isolated. Only 2 out of $10 \mathrm{Ura}^{+}$transformants in the case of the
CDR2 disruption in the CAF4-2 genetic background and only one 1 out of $33 \mathrm{Ura}^{+}$transformants in the case of the CDR2 disruption in the $\Delta c d r 1$ deletion mutant background had this correct genotype. The other transformants in both cases were still heterozygous for the gene deletions, since homologous recombination of the disruption cassette with the first disrupted $\Delta c d r 2$ : : his $G$ alleles rather than with the wild-type CDR2 alleles had occurred in both cases. Verification of the gene deletions in DSY653 and DSY654 was performed with Southern blot analysis using his $G$ as a probe. No signals other than those expected by the gene replacement of the wild-type alleles by the disrupted alleles were observed in this analysis, thus confirming the results obtained by PCR analysis with respect to the identification of the constructed mutants (data not shown). The $\Delta c d r 2$ homozygote deletion mutants created were then used in drug susceptibility assays.

\section{Drug susceptibility assays with $\Delta c d r 2$ and $\Delta c d r 1$ $\Delta c d r 2$ mutants}

Recently, the usefulness of multidrug transporter mutants for addressing the function of multidrug transporters and for assigning unrelated compounds as possible substrates of these proteins in C. albicans was reported (Sanglard et al., 1996). Since many of these compounds inhibit the growth of C. albicans, it is therefore possible to assign them to putative substrates of multidrug transporters by observing growth variations between different yeast types on agar plates containing the different inhibitors. A reduced growth of a given mutant in the presence of a defined inhibitor can be the consequence of an increased accumulation of the substance due to the absence of its specific efflux transporter. The previously constructed $\Delta c d r 1$ mutant DSY448 was shown in fact to be hypersusceptible, not only to azole antifungal agents, but also to other metabolic inhibitors (Sanglard et al., 1996). Fig. 7 presents these features and one can observe that every listed compound affected, but to different extents, the growth of DSY448 compared to the wild-type CAF2-1. When the $\Delta c d r 2$ deletion mutant DSY653 was exposed to the same array of compounds listed in Fig. 7, however, the growth of this mutant was surprisingly not affected. Only when the CDR2 gene deletion is constructed in a $\Delta c d r 1$ background can a more severe growth inhibition be observed compared to the single $\Delta c d r 1$ deletion mutant for almost every compound tested. Exceptions were found in plates containing nocodazole and crystal violet, where no difference in growth was found between the single $\Delta c d r 1$ and the double $\Delta c d r 1 \Delta c d r 2$ mutants. Intracellular concentrations of $\left[{ }^{3} \mathrm{H}\right]$ fluconazole were measured in these mutants to illustrate these observations, as indicated in Methods. Whereas the $\Delta c d r 2$ deletion mutant DSY653 accumulated approximately the same levels of fluconazole as the wild-type $(670 \pm 25$ and $718 \pm 21$ c.p.m. per $10^{9}$ cells, respectively), accumulation in the $\Delta c d r 1$ and the double $\Delta c d r 1 \Delta c d r 2$ mutants was increased by a factor of $2 \cdot 3$ and $3 \cdot 1$. These data are consistent with an increased susceptibility to fluconazole 


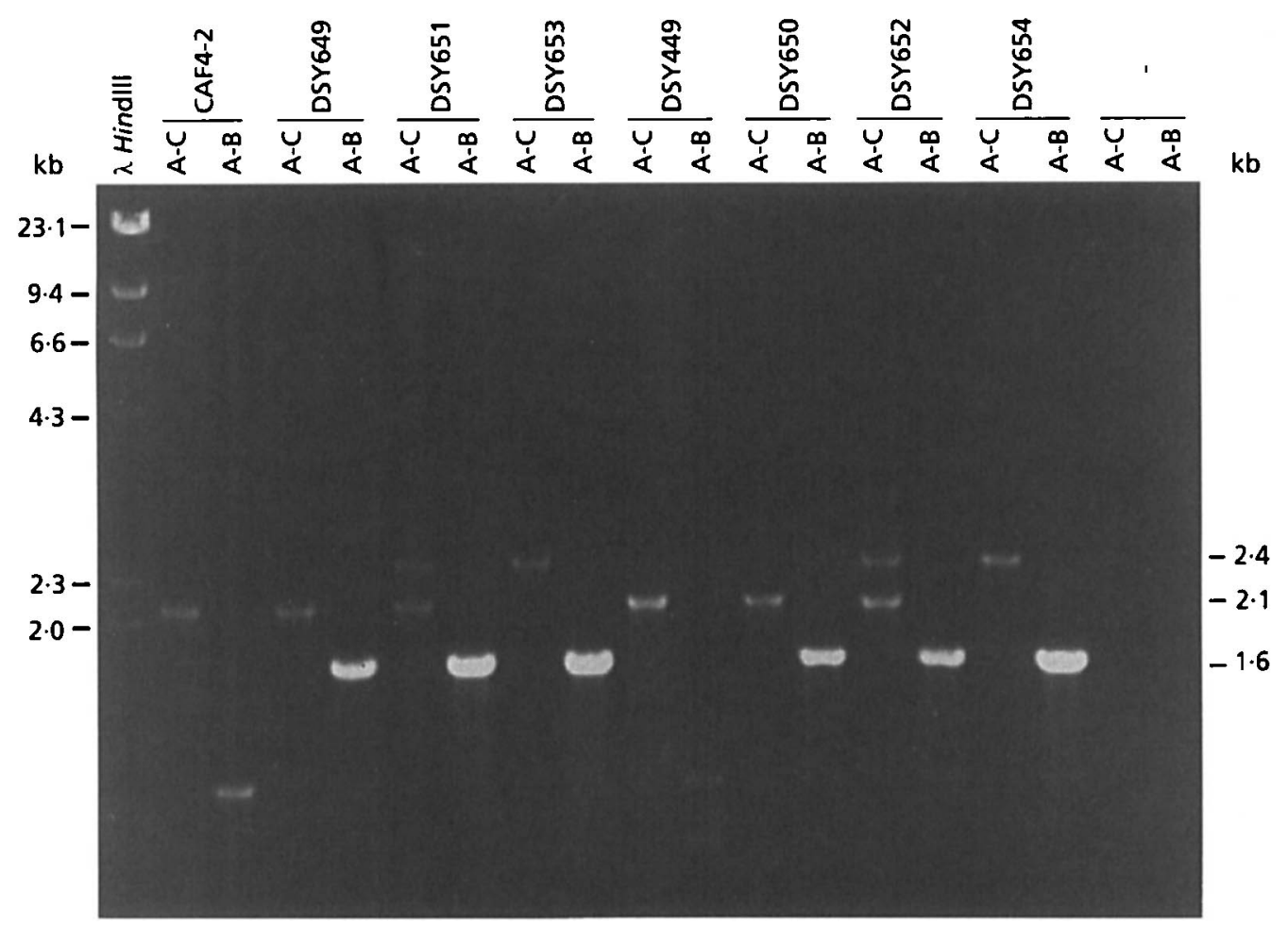

Fig. 6. PCR monitoring of the disruption of the CDR2 gene in CAF4-2 and in the $\Delta c d r 1$ deletion mutant DSY449. The sequences of the primers A, B and C are given in Fig. 5 . The expected product size for amplifications with primers A and B is $1.6 \mathrm{~kb}$ on a disrupted allele whereas no amplification should be obtained with the wild-type allele. The bands seen at $1 \mathrm{~kb}$ and sometimes at $0.8 \mathrm{~kb}$ using primers $A$ and $B$ and DNA from CAF4-2 and other isolates represent a background. Expected product sizes with primers $A$ and $C$ are 2.1 and $2.4 \mathrm{~kb}$ for the wild-type allele and the disrupted allele after 5 FOA treatment. These expected PCR product sizes correspond to those observed by horizontal gel electrophoresis. The origin of genomic DNA from each strain is indicated with the corresponding primers used for each PCR. Yeast genotypes are given in Table 1.

of the $\Delta c d r 1 \Delta c d r 2$ mutant DSY654 compared to the $\Delta c d r 1$ mutant DSY448 (Fig. 7).

The reason for the lack of hypersusceptibility of the $\Delta c d r 2$ deletion mutant was clearer when the mRNA levels of this gene were measured in the parent strain CAF2-1 or in other azole-susceptible strains. In fact, no CDR2 mRNA was detected in these cells (Figs 4 and 8 ), even in the $\Delta c d r 1$ mutant DSY447, which is the parent of the $\Delta c d r 1 \Delta c d r 2$ mutant DSY654 (data not shown). Taking these observations into account, it is expected that, when $C D R 2$ is deleted in these strains, no phenotypic effect with respect to drug susceptibility can be observed.

\section{CDR2 is expressed in multidrug transporter mutants reverting spontaneously to normal fluconazole susceptibility}

We observed that, after a prolonged incubation of the $\Delta c d r 1$ and $\Delta c d r 1$ sben deletion mutants DSY448 and DSY468 (which are described elsewhere; Sanglard et al., 1996) on plates containing fluconazole, some colonies spontaneously grew over a layer of spotted cells. The frequency at which these colonies appeared fluctuated between $1 \times 10^{-4}$ and $3 \times 10^{-4}$. Some of these cells were grown in drug-free YEPD medium and spotted again on plates containing fluconazole. To our surprise, five randomly chosen isolates, which were named R1-R5, were more resistant to fluconazole than their hypersusceptible parents. The same revertants regained resistance to ketoconazole and itraconazole (Table 3). This effect was not due to the expression of $B E N^{\mathrm{r}}$, since $\Delta c d r 1 \Delta b e n$ mutants generated spontaneous revertants at the same frequency, and since overexpression of $B E N^{r}$ can only render cells resistant to fluconazole. A Northern blot of RNA extracted from the revertant strains R1-R5 showed that CDR1 mRNA was, as expected, effectively absent from these cells, but that the CDR2 gene was expressed (Fig. 8). The level of this expression was low but significant in these cells when compared to the absence of expression in CAF2-1 or DSY447. Therefore it appears that the expression of CDR2 seems to be responsible for the reversion of R1-R5 to wild-type levels of susceptibility not only to fluconazole but also to itraconazole and ketoconazole. This result is not entirely unexpected given that CDR2 is clearly overexpressed in resistant strains (Fig. 4) and that it participates with CDR1 in the resistance of $C$. albicans to azole antifungal agents. 

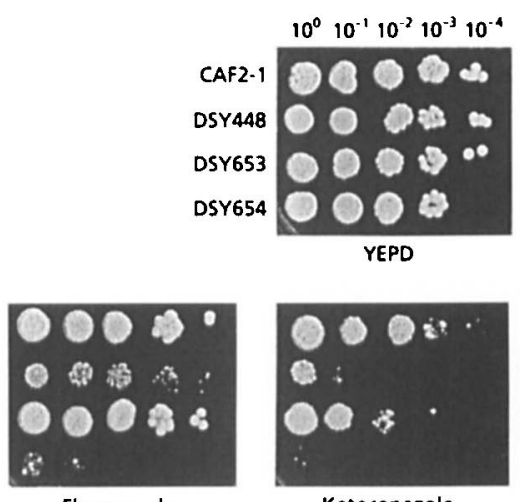

Fluconazole $\left(0.5 \mu \mathrm{g} \mathrm{ml}^{-1}\right)$

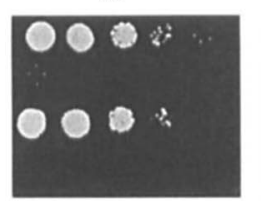

Terbinafine $\left(0.25 \mu \mathrm{gll}^{-1}\right)$

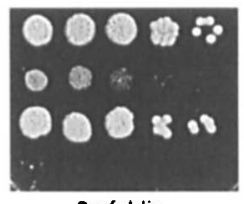

Brefeldin

$\left(7.5 \mu \mathrm{g} \mathrm{ml}^{-1}\right)$

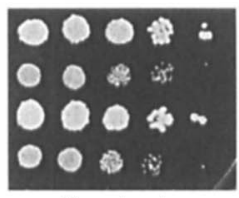

Nocodazole

$\left(10 \mu \mathrm{g} \mathrm{ml}^{-1}\right)$

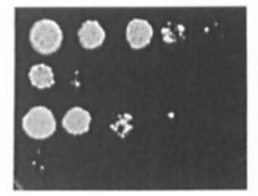

Ketoconazole $\left(0.003 \mu \mathrm{g} \mathrm{ml} l^{-1}\right)$

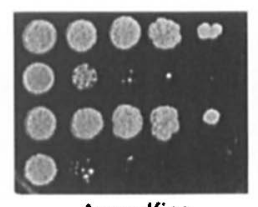

Amorolfine $\left(0.005 \mu \mathrm{g} \mathrm{ml}^{-1}\right)$

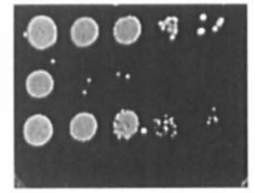

Fluphenazine $\left(50 \mu \mathrm{g} \mathrm{ml}^{-1}\right)$

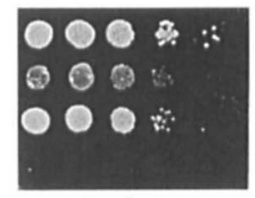
Cerulenin
$\left(0.75 \mu \mathrm{g} \mathrm{m} \mathbf{~}^{-1}\right)$

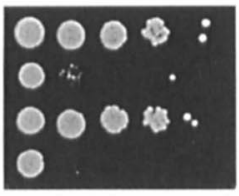

Itraconazole $\left(0.003 \mu \mathrm{g} \mathrm{ml}^{-1}\right)$

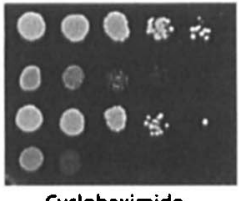

Cycloheximide (400 $\mu \mathrm{g} \mathrm{ml}^{-1}$ )

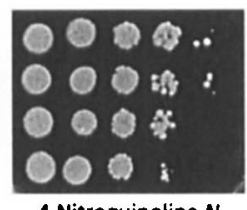

4-Nitroquinoline $N$ oxide $\left(005 \mu \mathrm{g} \mathrm{ml}^{-1}\right)$

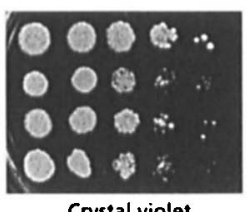

Crystal violet $\left(0.15 \mu \mathrm{g} \mathrm{ml} l^{-1}\right)$

Fig. 7. Susceptibility of multidrug transporter mutants DSY448, DSY653 and DSY654 to antifungal agents and metabolic inhibitors. Each strain was grown to exponential growth phase to a density of $2 \times 10^{7}$ cells ml ${ }^{-1}$ and $5 \mu \mathrm{l}$ was spotted in a dilution series on YEPD complex medium agar plates. Plates were incubated for $60 \mathrm{~h}$ at $30^{\circ} \mathrm{C}$. The concentration of compounds utilized in this study is indicated for each plate.

\section{DISCUSSION}

We report here the cloning of different C. albicans genes which conferred resistance to different antifungal agents, including azole derivatives, and to other unrelated metabolic inhibitors. Not only were the CDR1 and the $B E N^{\mathrm{r}}$ genes re-isolated by a screening procedure consisting of complementing the fluconazole hypersusceptibility of an $S$. cerevisiae $\Delta p d r 5$ mutant, but other additional genes were cloned using the same compound and with ketoconazole as a selective agent. Among these additional genes, a new $\mathrm{ABC}$ transporter gene closely related to $C D R 1$ was characterized and therefore named CDR2. Prasad et al. (1995) utilized a similar strategy to clone multidrug resistance genes with a similar $S$. cerevisiae mutant but using cycloheximide as a selective agent in the screening procedure and two C. albicans genomic libraries based on single copy and multicopy

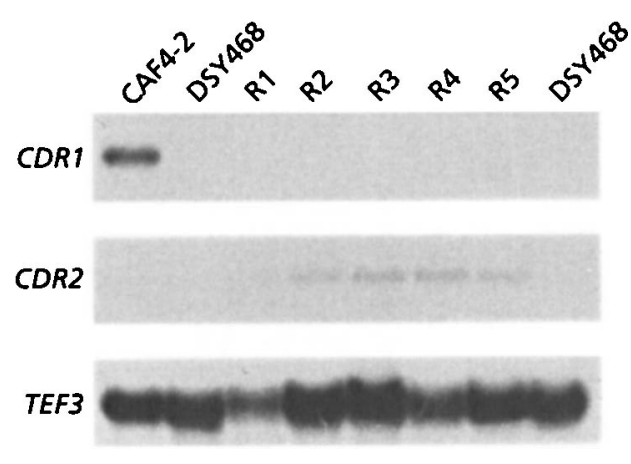

Fig. 8. Northern blot analysis of $C$. albicans multidrug transporter mutants R1-R5 reverting to wild-type susceptibility to fluconazole. CAF4-2 and DSY468 were included in this analysis. Membranes were hybridized sequentially with the $C D R 1, C D R 2$ and TEF3 probes. The design of the CDR1 and CDR2 probes is described in the legend of Fig. 4. After hybridization with the $C D R 1$ and $C D R 2$ probes, membranes were exposed for $48 \mathrm{~h}$ on an RX Fuji X-ray film at $-70^{\circ} \mathrm{C}$. The exposure time for the TEF3 probe was $3 \mathrm{~h}$.

Table 3. Multidrug transporter mutants reverting to wild-type levels of susceptibility to azole antifungal agents

See Table 2 for explanation of values and abbreviations.

\begin{tabular}{|llcccc|}
\hline $\begin{array}{l}\text { Strain } \\
\text { type }\end{array}$ & $\begin{array}{c}\text { Parent } \\
\text { strain }\end{array}$ & $\begin{array}{c}\text { YEPD } \\
\text { only }\end{array}$ & $\begin{array}{c}\text { Flu } \\
(\mathbf{0 \cdot 5})\end{array}$ & $\begin{array}{c}\text { Keto } \\
(\mathbf{0 \cdot 0 3})\end{array}$ & $\begin{array}{c}\text { Itra } \\
(\mathbf{0 \cdot 0 1 2 5})\end{array}$ \\
\hline CAF2-1 & SC5314 & 4 & 4 & 3 & 3 \\
DSY448 & DSY447 & 4 & 2 & 0 & 1 \\
DSY468 & DSY467 & 4 & 2 & 0 & 1 \\
R1 & DSY468 & 4 & 4 & 4 & 4 \\
R2 & DSY448 & 4 & 4 & 4 & 4 \\
R3 & DSY468 & 4 & 4 & 4 & 4 \\
R4 & DSY468 & 4 & 4 & 4 & 4 \\
R5 & DSY448 & 4 & 4 & 4 & 4 \\
\hline
\end{tabular}

vectors. Seventy-four different clones were isolated by these authors, which is much higher than in our case, although this result did not take into account the number of clones with overlapping restriction maps. The high number of clones obtained by Prasad et al. (1995) could have been due to the nature of the selective agent, which probably allows the cloning of genes whose action on drug resistance is much less specific than azole antifungal agents. Our preliminary data on the identity of the additional genes cloned in this study and which are different from $C D R 1, B E N^{\mathrm{r}}$ and $C D R 2$ suggest that pDS255 and pDS257 contained genes similar to $B E N^{\mathrm{r}}$ and to the $S$. cerevisiae transcription factor YAP1, respectively (D. Sanglard, unpublished).

The method of cloning resistance genes by functional complementation is of potential interest for obtaining similar genes from other pathogenic organisms. Candida glabrata and Candida krusei, for example, are organisms 
becoming more frequent in fungal infections and they exhibit lower intrinsic susceptibility to fluconazole than measured in C. albicans (Essayag et al., 1996; Johnson et al., 1995a; Odds et al., 1996). Some reports document resistance to azole antifungal agents in C. glabrata and C. krusei after prolonged exposure to these agents (Berrouane et al., 1996; Chavanet et al., 1994; Hitchcock et al., 1993; Parkinson et al., 1995; Vanden Bossche et al., 1992), so understanding mechanisms of resistance in these isolates is becoming more important.

Table 2 gives an overview of the pattern of resistance of the cloned genes to different classes of antifungal agents and metabolic inhibitors. Besides the resistance conferred to three important azole derivatives by overexpression of CDR1 and CDR2 in S. cerevisiae, it is noteworthy to mention the cross-resistance to other classes of antifungal agents such as terbinafine and amorolfine, which are used, as in the case of azole derivatives, in the treatment of different fungal infections. It is of interest that the expression of $B E N^{r}$ in the same host could make cells resistant to terbinafine and to a lesser extent to amorolfine. These features have an important impact for the treatment of fungal infections, since it is possible that resistance to azole antifungals mediated by the overexpression of multidrug transporters can extend to the other still-available antifungal agents.

The Cdr $2 p$ protein shares high similarity with Cdr1p, which in turn displays a high degree of similarity with the S. cerevisiae Pdr5p (Balzi et al., 1994; Bissinger \& Kuchler, 1994). The functional complementation of CDR1 and CDR2 in an S. cerevisiae multidrug transporter mutant $\Delta p d r 5$ allows the two gene products to be distinguished from each other by the differences in pattern of resistance to various substances. The Cdr2p protein seems to have a lower potency than Cdr1p in the degree of resistance conferred to $S$. cerevisiae, but gives a specific resistance to crystal violet. Interestingly, the $S$. cerevisiae gene $S G E 1$, which encodes a protein belonging to the class of major facilitators, also confers specific resistance to crystal violet when overexpressed (Ehrenhofer et al., 1994). Whether or not the differences in resistance patterns between $\mathrm{Cdr} 1 \mathrm{p}$ and $\mathrm{Cdr} 2 \mathrm{p}$ are due to amino acid substitutions between the two proteins remains to be determined; for example, the features observed for the two proteins may still not be valid in the context of expression in C. albicans, since the coding region of $C D R 2$, as opposed to $C D R 1$, contains three CUG codons (see Fig. 2) which are known to be translated to serine in this host and not to leucine as is the case in S. cerevisiae (Santos \& Tuite, 1995).

The most interesting feature of CDR2 at the moment is its regulation in C. albicans. As judged by the absence of CDR2 mRNA signals after autoradiography of the Northern blot shown in Fig. 4, CDR2 was not expressed at levels detectable by this method in clinical C. albicans strains susceptible to azole antifungal agents, but was overexpressed in isolates which became resistant to these agents. In a previous study (Sanglard et al., 1995), we showed that CDR1 was overexpressed in these strains. The probe for CDR1 generated at that time did not discriminate between $C D R 1$ and $C D R 2$ and thus the signal measured comprised the sum of the CDR1- and $C D R 2$-specific signals. The elevated expression of $C D R 1$ and CDR2 could be due to the action of the same or distinct transacting factors which remain to be characterized. The available sequence information on the promoters of both genes reveals no identical nucleotide regions and thus a common regulatory region cannot be assumed.

CDR2 expression can also be observed in multidrug transporter mutants when they revert spontaneously to wild-type levels of susceptibility to azole antifungal agents (Fig. 8; Table 3). The expression of CDR2 in these revertants can be considered a plausible explanation for this effect. Available data suggest that these revertants are even slightly more resistant than the wildtype parent CAF2-1 to azole derivatives (Table 3). Although we cannot exclude that other resistance factors may operate in these revertants, the restored CDR2 expression stresses the importance of this multidrug efflux transporter in the understanding of the mechanisms of resistance to azole antifungal agents in C. albicans.

The disruption of the CDR2 gene in C. albicans CAF42 did not result in hypersusceptibility to the substances tested in this study. Although CDR1 (which is present in this strain) may compensate for the deletion of $C D R 2$, it could also be argued that a residual $C d r 2 p$ activity might exist in the created homozygous $\Delta c d r 2$ deletion mutant. It was not possible to measure the absence of CDR2 mRNA in the created mutant, since the wild-type parent already did not exhibit detectable CDR2 expression. However, the data available on the identity of the homozygous $\Delta c d r 2$ deletion mutant allow us to ascertain a correct genotype. We believe that the lack of hypersusceptibility of the $\Delta c d r 2$ mutant reflects the absence of CDR2 expression in CAF4-2.

Several lines of evidence now suggest that multidrug transporter genes of the class of ABC transporters may be members of a larger multigene family in C. albicans. Besides the cloning of $C D R 1$ and $C D R 2$, preliminary data from a screening of a C. albicans genomic library with a conserved multidrug $A B C$ transporter gene probe resulted in the isolation of at least two distinct genes with similarity to the two genes mentioned above isolated by functional screening. It will be interesting to resolve the complexity of this gene family in the future and to determine if only specific members of this multigene family are involved in resistance to azole antifungal agents in C. albicans.

\section{ACKNOWLEDGEMENTS}

The authors thank the participation of S. Moirandat and J. Wyniger in cloning steps, the assistance of B. Ninet for sequencing and of $\mathrm{S}$. Sanglard for proofreading the manuscript. The authors thank K. Kuchler (University of Vienna Biocenter) for stimulating discussions and for providing the strain YKKB-13. This work was supported by a grant from the 
Office Fédéral de la Santé Publique no. 93.7125 to J.B. and D.S. and partially by a grant from the Swiss Research National Foundation no. 3100-045716 to D.S.

\section{REFERENCES}

Balzi, E., Wang, M., Leterme, S., Van Dyck, L. \& Goffeau, A. (1994). PDR5, a novel yeast multidrug resistance transporter controlled by the transcription regulator PDR1. J Biol Chem 269, 2206-2214.

Berrouane, Y. F., Hollis, R. J. \& Pfaller, M. A. (1996). Strain variation among and antifungal susceptibilities of isolates of Candida krusei. J Clin Microbiol 34, 1856-1858.

Bissinger, P. H. \& Kuchler, K. (1994). Molecular cloning and expression of the Saccharomyces cerevisiae STS1 gene product. A yeast $\mathrm{ABC}$ transporter conferring mycotoxin resistance. $J$ Biol Chem 269, 4180-4186.

Chavanet, P., Lopez, J., Grappin, M., Bonnin, A., Duong, M., Waldner, A., Buisson, M., Camerlynck, P. \& Portier, H. (1994). Cross-sectional study of the susceptibility of Candida isolates to antifungal drugs and in vitro in vivo correlation in $\mathrm{HIV}$-infected patients. AIDS 8, 945-950.

Chen, W. \& Struhl, K. (1988). Saturation mutagenesis of a yeast bis3 "TATA element": genetic evidence for a specific TATAbinding protein. Proc Natl Acad Sci USA 85, 2691-2695.

Ehrenhofer, M. A., Wurgler, F. E. \& Sengstag. C. (1994). The Saccharomyces cerevisiae SGE1 gene product: a novel drugresistance protein within the major facilitator superfamily. Mol Gen Genet 244, 287-294.

Essayag, S. M., Baily, G. G., Denning, D. W. \& Burnie, J. P. (1996). Karyotyping of fluconazole-resistant yeasts with phenotype reported as Candida krusei or Candida inconspicua. Int J Syst Bacteriol 46, 35-40.

Feinberg, A. \& Vogelstein, B. (1984). A technique for radiolabelling DNA restriction endonuclease fragments to high specific activity. Anal Biochem 17, 266-267.

Fling, M. E., Kopf, J., Tamarkin, A., Gorman, J. A., Smith, H. A. \& Koltin, Y. (1991). Analysis of a Candida albicans gene that encodes a novel mechanism for resistance to benomyl and methotrexate. Mol Gen Genet 227, 318-329.

Fonzi, W. A. \& Irwin, M. Y. (1993). Isogenic strain construction and gene mapping in Candida albicans. Genetics 134, 717-728.

Goldway, M., Teff, D., Schmidt, R., Oppenheim, A. B. \& Koltin, Y. (1995). Multidrug resistance in Candida albicans - disruption of the $B E N^{\mathrm{r}}$ gene. Antimicrob Agents Chemother 39, 422-426.

Hanahan, D. (1985). Techniques for transformation of E. coli. In DNA Cloning: a Practical Approach, pp. 109-135. Edited by D. M. Glover. Oxford: IRL Press.

Hitchcock, C. A., Pye, G. W., Troke, P. F., Johnson, E. M. \& Warnock, D.W. (1993). Fluconazole resistance in Candida glabrata. Antimicrob Agents Chemother 37, 1962-1965.

Hube, B., Monod, M., Schofield, D. A., Brown, A. J. P. \& Gow, N. A. R. (1994). Expression of seven members of the gene family encoding secretory aspartyl proteinases in Candida albicans. Mol Microbiol 14, 87-99.

Johnson, E. M., Davey, K. G., Szekely, A. \& Warnock, D. W. (1995a). Itraconazole susceptibilities of fluconazole susceptible and resistant isolates of five Candida species. J Antimicrob Chemother 36, 787-793.

Johnson, E. M., Warnock, D. W., Luker, J., Porter, S. R. \& Scully, C. (1995b). Emergence of azole drug resistance in Candida species fom HIV-infected patients receiving prolonged fluconazole therapy for oral candidosis. J Antimicrob Chemother 35, 103-114.
Marichal, P. \& Vanden Bossche, H. (1995). Mechanisms of resistance to azole antifungals. Acta Biochim Pol 42, 509-516.

Monod, M., Togni, G., Hube, B. \& Sanglard, D. (1994). Multiplicity of genes encoding secreted aspartic proteinases in Candida species. Mol Microbiol 13, 357-368.

Needleman, S. B. \& Wunsch, C. D. (1970). A general method applicable to the search of similarities in the amino acid sequence of two proteins. $J$ Mol Biol 48, 443-453.

Odds, F. C. (1996). Resistance of clinically important yeasts to antifungal agents. Int J Antimicrob Agents 6, 145-147.

Odds, F. C., Schmid, J. \& Soll, D. R. (1990). Epidemiology of Candida infections in AIDS. In Mycoses in AIDS Patients, pp. 67-74. Edited by H. Vanden Bossche, D. W. R. Mackenzie, G. Cauwenberg, J. Van Custem, E. Drouhet \& B. Dupont. New York: Plenum Press.

Odds, F. C., Dams, G., Just, G. \& Lewi, P. (1996). Susceptibilities of Candida $s p p$ to antifungal agents visualized by two-dimensional scatterplots of relative growth. Antimicrob Agents Chemother $\mathbf{4 0}$, 588-594.

Parkinson, T., Falconer, D. J. \& Hitchcock, C. A. (1995). Fluconazole resistance due to energy-dependent drug efflux in Candida glabrata. Antimicrob Agents Chemother 39, 1696-1699.

Powderly, W. G. (1994). Resistant candidiasis. AIDS Res Hum Retroviruses 10, 925-929.

Prasad, R., Dewergifosse, P., Goffeau, A. \& Balzi, E. (1995). Molecular cloning and characterization of a novel gene of Candida albicans, CDR1, conferring multiple resistance to drugs and antifungals. Curr Genet 27, 320-329.

Rex, J. H., Rinaldi, M. G. \& Pfaller, M. A. (1995). Resistance of Candida species to fluconazole. Antimicrob Agents Chemother 39, 1-8.

Sanglard, D., Kuchler, K., Ischer, F., Pagani, J. L., Monod, M. \& Bille, J. (1995). Mechanisms of resistance to azole antifungal agents in Candida albicans isolates from AIDS patients involve specific multidrug transporters. Antimicrob Agents Chemother 39, 2378-2386.

Sanglard, D., Ischer, F., Monod, M. \& Bille, J. (1996). Susceptibilities of Candida albicans multidrug transporter mutants to various antifungal agents and other metabolic inhibitors. Antimicrob Agents Chemother 40, 2300-2305.

Santos, M. \& Tuite, M. F. (1995). The CUG codon is decoded in vivo as serine and not leucine in Candida albicans. Nucleic Acids Res 23, 1481-1486.

Vanden Bossche, H., Marichal, P., Odds, F., Lejeune, L. \& Coene, M.-C. (1992). Characterization of an azole-resistant Candida glabrata isolate. Antimicrob Agents Chemother 36, 2602-2610.

Vanden Bossche, H. V., Warnock, D. W., Dupont, B., Kerridge, D., Sengupta, S., Improvisi, L., Marichal, P., Odds, F. C., Provost, F. \& Ronin, O. (1994a). Mechanisms and clinical impact of antifungal drug resistance. J Med Vet Mycol 32 (Suppl. 1), 189-202.

Vanden Bossche, H., Marichal, P. \& Odds, F. C. (1994b). Molecular mechanisms of drug resistance in fungi. Trends Microbiol 2, 393-400.

Vuffray, A., Durussel, C., Boerlin, P., Boerlin, P. F., Bille, J., Glauser, M. P. \& Chave, J. P. (1994). Oropharyngeal candidiasis resistant to single-dose therapy with fluconazole in HIV-infected patients. AIDS 8, 708-709.

Received 23 July 1996; revised 30 September 1996; accepted 8 October 1996. 